\title{
Proceedings
}

\section{Educational STEM Project Based on Programming ${ }^{\dagger}$}

\author{
Elena Segade ${ }^{1, *}$, Jose Balsa ${ }^{2}$ and Carmen Balsa ${ }^{3}$ \\ 1 Faculty of Education, Universidade da Coruña (University of A Coruña), 15071 Elviña, Spain \\ 2 CITIC, Universidade da Coruña (University of A Coruña), 15071 Elviña, Spain \\ 3 IES As Mariñas, 15300 Betanzos, Spain \\ * Correspondence: elena.segade.pampin@udc.es \\ + Presented at the Presented at the XoveTIC Congress, A Coruña, 5-6 September 2019.
}

Published: 5 August 2019

\begin{abstract}
We propose a sequence of activities to be programmed to improve the learning of Science, Technology, Engineering and Mathematics in Secondary Education. This proposal consists on generate and transform images and figures programming in Octave. This enables the students to use basic and iterative instructions to construct a complex program, understand and structure problems, logic reformulation of problems, design of systematic processes for the resolution, generalization and comparison of solutions. Initial analyses of the implementation of the activities will be presented.
\end{abstract}

Keywords: STEM; educational innovation; modular programming

\section{Introduction}

The continuous development of a technological society makes teaching practices adapt to this changing reality. In this sense, the education should try to reflect the interconnection between subjects through a globalized curriculum [1]. So that, interdisciplinary teaching plays a fundamental role in the integral formation of people and improve the teaching and learning processes [2].

The students have the initial approach to the programming at the first courses of the Spanish Secondary Education. This teaching proposal is aimed to the students who start programming. We wanted to create learning resources using free software open to all.

The proposal consists in the elaboration of a set of modules based on the free software. Octave oriented to solve specific problems for the STEM area of the second year of Spanish Secondary Education in the subjects of Mathematics, Physics and Chemistry, Technology and Programming.

Our interdisciplinary teaching proposal uses basic instructions to model a mathematical problem and to explore the different rigid movements of the plane [3]. Besides, it has a positive impact in the learning of Physics and Chemistry through programming instructions to decompose an image in primary colours to knowing the decomposition of light in the visible spectrum. In this way, are solving technological problems in a programming environment that is the aim of the subject of Technology.

\section{Proposed Activities}

The main motivation of the project is to provide a programming learning tool. The platform is composed of modules that can be used in the STEM area. This proposal is free and open software created to provide resources to teachers. In addition, students can learn the importance of planning a project using the tools at their disposal for: 
- Plan requirements using existing tools or modifying them.

- Simplify the programming language that use variables not previously defined.

- Execute, verify output and detect errors.

This proposal consists on programming using "GNU Octave" to transform images and figures. The algorithms have been programmed in sets of blocks or functions. The type of functions implemented are: load or generate an image or polygon, movements in the plane, color decomposition in primary colors, mosaics and friezes.

\section{Results and Conclusions}

The evaluation of activities consists of an initial and a final evaluation. The initial evaluation will help us to know the initial competences of the students. The comparison of both evaluations allows us to check their knowledge before and after the activities. The analysis of the evaluation results has been descriptive.

In the activity of measure the perimeter and area of a random polygon generate with a module (Figure 1), we observed that it is easier for them to calculate the area and the calculations of area and perimeter improved with respect to the initial results.

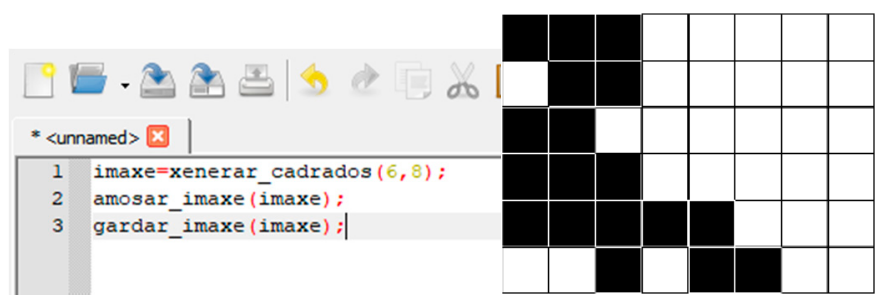

Figure 1. Example of code and output to generate random polygon over a grid.

In the activity of symmetry (Figure 2), we detected that through the programming its visualization improved, and they describe and verify better the properties that define it. As in the mosaics and friezes activity, students can easily explore direct and inverse movements in the plane.
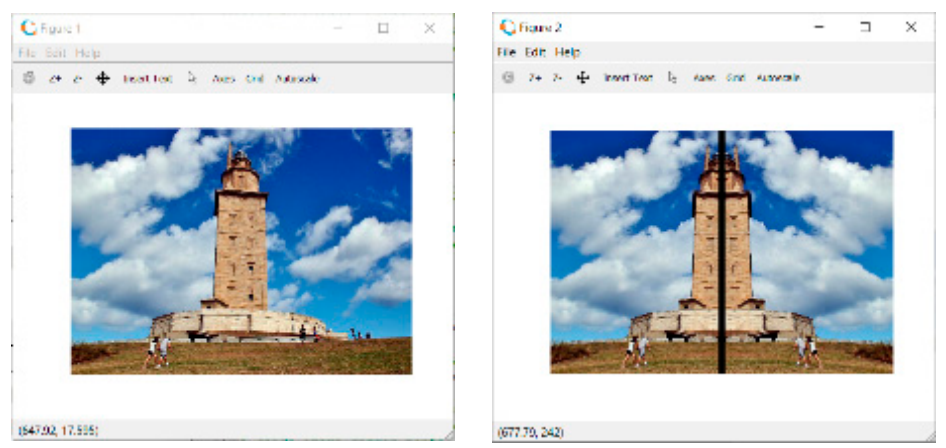

Figure 2. Example of two symmetries.

So that, it is an innovative teaching proposal oriented to use new technologies that can significantly improve the learning of Science, Technology, Engineering and Mathematics (STEM). In particular, the block programming improves the logical and mathematical reasoning, problem solving, structuring of ideas and graphic and spatial visualization. This could hardly be possible to make it work using traditional teaching methods (blackboard, paper and pencils). 


\section{References}

1. Torres, J.; Globalización e Interdisciplinariedad: El Currículum Integrado; Morata: Madrid, Spain, 2012. Available online: http://www.terras.edu.ar/biblioteca/1/CRRM_Torres_Unidad_2.pdf (accessed on 31 July 2019).

2. Quesada, J.F.; Videojuegos matemáticos con Scratch. 2015. Available online: https://blogsaverroes. juntadeandalucia.es/viiencuentro-matematicas-sevilla/files/2017/10/T8.pdf (accessed on 31 July 2019).

3. Gutiérrez, A.; Jaime, A. Reflexiones sobre la enseñanza de la geometría en primaria y secundaria. Tecné, Episteme y Didaxis: TED 2012, 32, 55-70.

(C) 2019 by the authors. Licensee MDPI, Basel, Switzerland. This article is an open access article distributed under the terms and conditions of the Creative Commons Attribution (CC BY) license (http://creativecommons.org/licenses/by/4.0/). 